\title{
Why (and When) Straight Women Trust Gay Men: Ulterior Mating Motives and Female Competition
}

\author{
Eric M. Russell ${ }^{1} \cdot$ Vivian P. Ta $^{1} \cdot$ David M. G. Lewis $^{2} \cdot$ Meghan J. Babcock $^{1}$. \\ William Ickes ${ }^{1}$
}

Received: 12 January 2015 / Revised: 9 October 2015 / Accepted: 10 October 2015 / Published online: 17 November 2015

(C) Springer Science+Business Media New York 2015

\begin{abstract}
Previous findings indicate that heterosexual women experience a greater sense of comfort and trust in their friendships with gay men than in their friendships with heterosexual individuals. In the present studies, we tested a hypothesis that not only explains why women exhibit increased trust in gay men but also yields novel predictions about when (i.e., in what contexts) this phenomenon is likely to occur. Specifically, we propose that gay men's lack of motives to mate with women or to compete with them for mates enhances women's trust in gay men and openness to befriend them. Study 1 demonstrated that women placed greater trust in a gay man's mating — but not non-mating (e.g., career) advice - than in the same advice given by heterosexual individuals. Study 2 showed that women perceived a gay man to be more sincere in scenarios relevant to sexual and competitive mating deception. In Study 3, exposing women to a visualization of increased mating competition enhanced their trust in gay men; when mating competition was salient, women's trust in mating information from a gay man was amplified. Study 4 showed that women who perceived higher levels of mating competition were more open to befriending gay men. Together, these converging findings support our central hypothesis, which not only provides a distal explanation for the trust that straight
\end{abstract}

Eric M. Russell

eric.russell@mavs.uta.edu

1 Department of Psychology, The University of Texas at Arlington, Box 19528, Arlington, TX 76019, USA

2 Department of Psychology, Bilkent University, 06800 Bilkent, Ankara, Turkey women place in gay men, but also provides novel insights into previously unidentified contexts that facilitate the formation and strengthening of this unique bond.

Keywords Heterosexual women · Homosexual men . Friendship · Human mating · Intrasexual competition . Gay-straight psychology

\section{Introduction}

The literature detailing friendships between straight women and gay men has just begun to take form; many text qualitative studies have started to identify the significance of the unique, trusting bond that straight women and gay men share with one another (de la Cruz \& Dolby, 2007; Gaiba, 2008; Grigoriou, 2004; Hopcke \& Rafaty, 1999, Malone, 1980). Specifically, women with gay male friends-often known as "fruit flies" or "fag hags" in the gay male community (Maitland, 1991; Moon, 1995; Thompson, 2004; Warren, 1976)—report having more open and intimate conversations; more social and emotional support that would take the form of companionship, sympathy, or advice; and a greater interpersonal connection with a male presence (Grigoriou, 2004). These positive interactions that women frequently experience with gay men are regarded as unique and are not necessarily present in their friendships with straight men or women. For example, straight women feel more comfortable trusting gay men when they discuss significant aspects of their romantic lives - topics that they are usually reluctant to openly discuss with their straight male or female friends (Grigoriou, 2004; Hopcke \& Rafaty, 1999).

An important reason for this heightened trust in gay men may be the absence of ulterior mating motivations that frequently complicate women's relationships with straight men (e.g., onesided sexual interest; Abbey, 1982; DeSouza, Pierce, Zanelli, 
\& Hutz, 1992) and with other straight women (e.g., mating competition; Buss, 1988; Buss \& Dedden, 1990; Fisher \& Cox, 2010). Recent experimental evidence corroborates this view. Russell, DelPriore, Butterfield, and Hill (2013) found that women who received mating-related advice from a gay man placed greater trust in that advice than did women who received the same advice from either a straight woman or straight man. However, this previous research was limited in that it did not discriminate between mating-related advice and advice relevant to other important life domains. If it is the absence of ulterior mating motives that leads straight women to place greater trust in gay men, then (1) women's heightened trust in gay men should be specific to mating contexts, and (2) women's heightened perceptions of competition within this domain should enhance their trust in gay men.

\section{Women's Mating-Specific Trust in Gay Men}

Straight women should exhibit heightened trust in gay men in domains in which the desires of other heterosexual individuals conflict with their own interests. Mating contexts represent an important domain of life in which other heterosexual individuals may attempt to mislead straight women due to conflicting mating strategies and desires. For example, in their competition for mates, other heterosexual women may misinform female competitors about potential mating opportunities to reduce the threat of competition (i.e., competitor manipulation) (Fisher \& Cox, 2010). Because this strategy often involves one woman giving another woman misleading information about her physical appearance or a man's sexual interest in her, women may not view other women's suggestions as objective or honest in mating contexts. Information that women receive from straight men may also be untrustworthy because straight men - who by definition are sexually attracted to women - may have their own sexual interests in mind. On the other hand, because gay men neither are in competition with nor seek straight women as mates, gay men's mating motivations should not be in conflict with straight women's own mating interests. This reasoning suggests that unbiased mating-relevant information may be a unique benefit that women are particularly likely to gain from their relationships with gay men (Russell et al., 2013).

Indeed, previous research findings indicate that gay men are equipped to provide women with advice that can be of service to their romantic relationships with straight men (Rumens, 2008). Unlike straight men, gay men are able to look past a woman's physical attributes and provide her with direct and honest advice about relationships, dating, and sex (Muraco, 2004; Singleton, 2005). Thus, gay men's ability to provide women with mating-related information in the absence of sexual interest may contribute to women's trust in their advice that could be useful in mating contexts.

\section{Study 1: Is Women's Trust in Gay Men Rooted in the Mating Domain?}

Study 1 sought to (1) replicate the finding that women place greater trust in gay men's mating-related advice (Russell et al., 2013), and (2) determine whether women's heightened trust in gay men's advice is specific to mating contexts. Because we hypothesize that gay men's absence of ulterior mating motivations contributes to women's heightened trust in gay men, we predicted that this effect would be pronounced within mating contexts. In non-mating contexts, however, there are no clear reasons that straight women should face lower levels of competition from gay men than from heterosexual individuals. For example, straight women and gay men who pursue similar career paths may compete with one another for job positions or professional recognition (e.g., Wilson, 2005). Accordingly, career-related advice offered to a woman from a gay man might be intentionally misleading because both individuals are in competition for a single position. We therefore predicted that (1) women would trust a gay male target's mating advice more than the same advice offered from a heterosexual male or female, and (2) this effect would not be present when women evaluated non-mating-related (e.g., career) advice offered by the same individuals.

\section{Method}

\section{Participants}

A total of 167 heterosexual women $\left(M_{\text {age }}=19.82\right.$ years, $S D_{\text {age }}=$ 2.53) were recruited from the subject pool of a large, public university in the United States and received partial course credit for their participation. The sample was 39\% Caucasian, $29 \%$ Hispanic, $17 \%$ African American, and 15\% Asian.

\section{Measures and Procedure}

Target Stimuli The different conditions were generated using different target individuals. Each condition involved viewing a target individual's social media profile which contained (1) the image of the target, (2) the gender of the target, and (3) the sexual orientation of the target. However, the sex and sexual orientation of the target individual varied across conditions: one profile belonged to a straight female, another to a straight male, and the third to a gay male. The target's sex and sexual orientation were indicated by the photograph and by the text on the profile page, respectively.

The same male photograph was used for both the straight and gay male profiles to enhance experimental control, and we selected a photograph of a female target that appeared to be 
about the same age as the male target. To ensure that the male and female photographs did not vary in perceived age, an independent sample of judges $(n=13)$ estimated how old they thought the male and female targets were. There was no perceived age difference between the two targets, $t(12)<1$, $n$ s.

Participants completed the study online and were randomly assigned to one of the three conditions (i.e., straight female, straight male, or gay male target). After the participants viewed the target individual's profile page, they were asked to imagine receiving advice from the target in 10 different scenarios: five directly related to mating and five related to career (i.e., nonmating) pursuits.

The five mating-related items paralleled those used by Russell et al. (2013). For example, participants were asked to imagine interacting with an attractive member of the opposite sex and then receiving mating-related information from the target such as: "I don't think he was into you, I would pursue someone else." The five novel items related to career (i.e., non-mating) pursuits included, for example, a scenario in which the participant was advised by the target: "I don't think that company is a good fit for you, I would apply elsewhere." For each item, participants were asked to rate the likelihood that they would trust the target's advice (7-point Likert-type scale; $1=$ very unlikely, $7=$ very likely).

At the end of the experiment, participants were asked to report the sexual orientation of the target that they viewed in the Facebook profile. We excluded from our analysis the data for participants who failed to correctly report the sexual orientation of the target $(n=11)$.

\section{Results}

We computed two composite trust scores by summing the item scores for the participant's trust in each target's mating advice $(\alpha=.76)$ and career advice $(\alpha=.84)$. We then performed a $3 \mathrm{X}$ 2 mixed model ANOVA that tested the effects of the sex and sexual orientation of the advice giver (straight female vs. straight male vs. gay male), and the domain in which the advice was given (mating vs. career) on the participants' trust. The significant interaction between the sex and sexual orientation of the advice giver and the type of advice given, $F(2,150)=3.21, p=.04, \eta_{\mathrm{p}}^{2}=.04$, indicated that differential trust in gay men was contingent on the life domain in which the advice was given. As predicted, women differentially trusted the three targets' mating advice, $F(2,150)=$ $6.66, p<.01, \eta^{2}=.08$. Pairwise comparisons (Bonferroni correction) revealed that, as hypothesized, women who received mating advice from the gay male target were more likely to trust that advice $(M=3.93, S D=1.20)$ than women who received the same advice from either a straight male $(M=3.20, S D=1.02)$, $p<.01, d=.66$, or a straight female $(M=3.33, S D=1.00)$, $p=.02, d=.54$ (see Fig. 1). In contrast, women did not differentially trust gay men's, straight women's, and straight men's

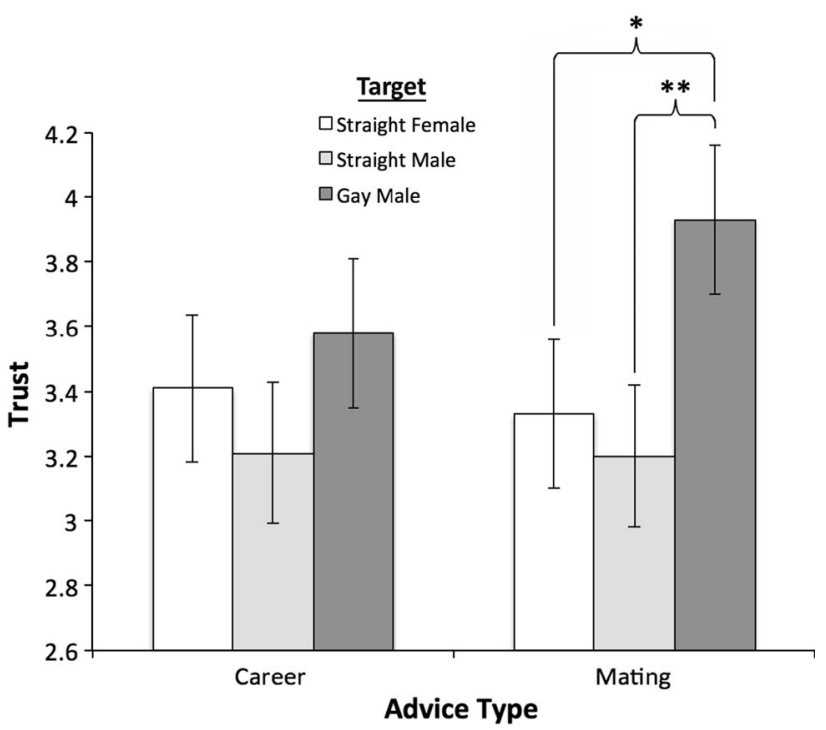

Fig. 1 Women's trust in mating versus career advice from straight women, straight men, and gay men (Study 1). Note Full scale runs from 1 to 7. Bars represent \pm 1.5 SE. Asterisks above bars indicate significant pairwise comparisons. ${ }^{*} p<.05 ; * * p<.01$

career-related advice; there was no significant effect of target on women's trust in this non-mating-related domain, $F(2,150)=$ 1.72 .

\section{Discussion}

The results of Study 1 supported the hypothesis that women's heightened trust in gay men was specific to the mating domain: straight women trusted a gay man's mating - but not careeradvice more than the same advice offered by heterosexual men or women. In addition to replicating the finding from previous research that straight women are particularly likely to trust the mating advice of gay men (Russell et al., 2013), these results lend further support to the hypothesis that the absence of ulterior mating motivations in straight female-gay male dyads is the specific reason for straight women's heightened trust in gay men.

\section{Study 2: The Absence of Gay Men's Deceptive Mating Intentions}

Although Study 1 demonstrated that straight women's trust in gay men was specific to mating-related concerns, it remains unclear whether gay men's absence of ulterior mating motivations (i.e., sexual or competitive intentions) contributes to women's trust in gay men. Trust is a multifaceted construct with different components: (1) benevolent trust, (2) integrity, and (3) perceived expertise in the relevant subject matter 
(Colquitt, Scott, \& LePine, 2007; Mayer, Davis, \& Schoorman, 1995). The logic underlying our central hypothesis points toward women's heightened trust in gay men having its roots in benevolent trust, given that gay men should not possess motives to deceive women in mating contexts.

Because we hypothesize that women's heightened trust in gay men results from gay men's absence of ulterior mating motivesand therefore gay men providing honest and impartial advicewomen should perceive gay men's mating-relevant information to be free from pretense or deceit. Accordingly, we predicted that, in mating-related situations with the potential for women to fall victim to sexual or competitive deception, women would perceive information provided from a gay man to be more sincere than the same information provided by a straight man or woman.

\section{Method}

\section{Participants}

A total of 272 heterosexual women $\left(M_{\text {age }}=20.30\right.$ years, $S D_{\text {age }}=$ 3.67) participated in the study for partial course credit. The study sample comprised $28 \%$ Caucasian, $29 \%$ Hispanic, $18 \%$ African American, $17 \%$ Asian, and $8 \%$ identified with other ethnicities.

\section{Measures and Procedure}

Scenarios Twelve different scenarios represented situations in which a "target individual" gave potentially deceptive information to a "receiver."Six of these scenarios were relevant to sexual deception; the information that the target individual provided to the receiver indicated that the target had a potential motive to sexually exploit the receiver. For example, one scenario was: "Imagine that the party is coming to a close, and you are quite tipsy. You are thinking about calling a taxi to take you home. When you say goodbye to [the target], he tells you: Don't worryI will walk you to my place that's down the street. I will let you sleep there."

The other six scenarios were relevant to competitive deception; the information that the target provided to the receiver indicated that the target had a potential motive to lessen the chances that the receiver could attract a desirable mate. For example, one of these scenarios read: "Imagine that [the target] approaches the attractive man that you've had your eyes on. [The target] comes back to tell you about their conversation with the man and says: I pointed you out to him, but he didn't seem interested. Darn..." (see "Appendix 1" section for the full list of scenarios).

Target Stimuli We generated four social media profiles that contained different target individuals from the ones used in Study 1 . Using the same male target photograph, we created profiles that depicted either a straight male or a gay male, as indicated by the sexual orientation information that was within the profile, and then paired these profiles with the scenarios illustrating potential sexual deception. With the exception of the sexual orientation information that we manipulated within the profile, the profiles were identical. Similarly, we created two profiles depicting a straight female and gay male target, respectively, and paired them with the scenarios relevant to mating competition.

The female participants completed the experiment online. Half of the women were randomly assigned to view scenarios relevant to sexual deception, and the other half were assigned to view scenarios relevant to competitive deception. Using a betweensubjects design for this experiment, women who were assigned to view the scenarios relevant to sexual deception viewed the online profile belonging either to (1) the straight male target or (2) the gay male target. Women who were randomly assigned to view scenarios relevant to mating competition viewed the online profile belonging to either a (1) straight female target or (2) a gay male target. Both groups of female participants were instructed to imagine that they themselves were the "receivers" of the information from the target individual. Participants indicated whether they thought the target was being sincere in each of the six scenarios on a 7-point Likert-type scale (endpoints: $1=$ very insincere, $7=$ very sincere).

\section{Results}

We excluded the data of one participant who failed to correctly identify the sexual orientation of the targets and created composite scores across the scenarios relevant to sexual deception $(\alpha=.83)$, and competitive deception $(\alpha=.81)$. We then conducted independent-samples $t$ tests to test whether women would perceive a gay male's statements to be more sincere than a straight male's statements in situations relevant to sexual deception, and a gay male's statements to be more sincere than another straight female's statements in situations relevant to competitive deception. As predicted, women perceived the gay male target to be more sincere $(M=3.74, S D=1.25)$ than the straight male target $(M=2.85, S D=0.86)$ in scenarios relevant to sexual deception, $t(135)=4.92, p<.001, d=.83$. Also as predicted, women perceived a gay man to be more sincere $(M=4.11, S D=1.02)$ than a straight woman in the scenarios relevant to mating competition $(M=3.48, S D=0.94), t(134)=3.73, p<.001, d=.64$.

\section{Discussion}

Because gay men were rated as being more sincere than either a straight male or a straight female in scenarios in which women had the potential to fall victim to sexual and competitive deception, respectively, women's heightened trust is likely rooted in gay men's perceived benevolence in the mating domain. It is important to point out, however, that we only examined whether women perceived gay men to be honest with the information that they provide in mating contexts. We did not examine 
whether gay men have a greater expertise in mating contexts, which may also have an impact on women's trust. Although future research is needed to further explore this possibility, the current findings suggest that gay men are indeed perceived to offer advice that is sincere, rather than cynically manipulative, in situations in which women are likely to be concerned about the possibility of either sexual deception or competitive deception.

\section{Study 3: The Effect of Mating Competition on Trust in Gay Men}

The results of Study 1 and Study 2 were consistent with our hypothesis that the lack of ulterior mating motives contributes to straight women's heightened trust in gay men. However, a closer examination of the nature of straight women's ulterior mating motivations leads to an even more nuanced set of predictions about straight women's psychology in the context of their relationships with gay men.

Previous research has revealed that heterosexual women's interests conflict with one another in their competition for mates (Buss, 1988; Buss \& Dedden, 1990). Women possess an array of competitive mating strategies (e.g., deception, competitor manipulation) that may be used to decrease other women's interest in potential mates and value in the eyes of potential mates (De Block \& Dewitte, 2007; Fisher \& Cox, 2010; Walters \& Crawford, 1994). However, the incidence of these competitive tactics often depends on the degree of mating competition in the environment (de Jong, Forsgren, Sandvik, \& Amundsen, 2012). Under heightened mating competition (e.g., more female competitors than potential male suitors), women should be more likely to employ these strategies. As a consequence, women in highly competitive mating contexts may be more motivated to deceive other women with inaccurate information related to mating. The increased risk for receiving tainted information from other women in these contexts may result in women placing even greater priority on information from individuals who are not motivated by ulterior mating motives (i.e., gay men). On this basis, we predicted that making mating competition salient by exposing women to a visualization of increased mating competition would result in even greater amplification of their trust in gay men's mating advice.

\section{Method}

\section{Participants}

A total of 128 heterosexual women $\left(M_{\text {age }}=19.22\right.$ years, $S D_{\text {age }}$ $=1.92$ ) participated in the study and received partial course credit for their participation. The sample was $31 \%$ Caucasian, $25 \%$ Hispanic, $10 \%$ African American, $25 \%$ Asian, and $9 \%$ of other ethnicities.

\section{Measures and Procedure}

Guided Visualization For the competition condition, we created a fictitious news article that described an increasing number of females and a dwindling number of males on college campuses around the nation, and which emphasized the increasing competition women were experiencing in trying to get a date on campus. This article was created in Adobe Photoshop and designed to appear like a real article from a newspaper website. The control condition used a second article that had the same appearance and formatting, as well as a parallel word count, but which discussed sex-specific sleep patterns (see “Appendix 2" section for the full text of both articles).

Target Stimuli Two social media profiles were created in Adobe Photoshop to depict two targets, a straight woman and a gay man, in this within-subject design. To ensure that the results from our previous two studies were not a spurious result specific to the target individuals presented, we again used photographs of different male and female targets in Study 3.

Mating-Relevant Scenarios Five vignettes described scenarios in which the two targets advised the participant about situations with potential mating-relevant outcomes. For example, one scenario read: "Imagine that you see a really attractive man in the corner of the room, and you want to go introduce yourself. However, you ate some spinach dip earlier, and you are worried some of it might be stuck in your teeth. How likely would you be to trust [the straight female target's name] to tell you that you have something stuck in your teeth before you go to talk to this man? ... How likely would you be to trust [the gay male target's name] to tell you that you have something stuck in your teeth?" Participants responded on 7-point Likert-type scales ( $1=$ very unlikely, $7=$ very likely $)$.

Participants completed the experiment at individual computer terminals in a psychological research laboratory. A researcher told the participants that they would be participating in an experiment about memory. Participants were randomly assigned to read one of the two fictitious newspaper articles for the alleged memory task. To encourage participants to read the article in its entirety, they were told that they would be quizzed at the end of the experiment on the article's content.

Participants were then asked to complete a second task related to social media profiles, under the premise that sufficient time needed to pass before assessing their memory about the article. After being presented with the social media profiles of the straight woman and the gay man, participants read the five mating-relevant scenarios and were asked to indicate their likelihood of trusting the straight woman and the gay man in each of the scenarios. 


\section{Results}

Prior to data analysis, we identified and excluded the data from participants who either failed to correctly identify the sexual orientation of the targets $(n=15)$ or could not correctly recall any information about the news article $(n=4)$. We then created composite trust scores for the straight woman $(\alpha=.70)$ and the gay man $(\alpha=.75)$ by summing participants' trust in these targets.

Consistent with our Study 1 findings, paired samples $t$ tests indicated that, in the mating contexts depicted, the straight women reported that they would trust the advice of gay men more $(M=$ 4.76, $S D=0.92)$ than that of other heterosexual women $(M=$ $4.08, S D=1.18), t(108)=5.13, p<.001, d=.50$. This effect was found for both the women in the control condition, $t(54)$ $=2.18, p=.03$, and the women in the competition condition, $t(53)=5.33, p<.001$.

To test our novel Study 3 prediction that women's prioritization of mating information from gay men would be amplified in the competition condition, we computed differential trust scores for each participant by subtracting their trust in the straight woman from their trust in the gay man. We then conducted an independent-samples $t$ test to test for differences in this differential trust across conditions. Precisely as predicted, the differential trust that women in the competition condition placed on mating-related information from the gay man was significantly greater than the more modest prioritization of gay men's advice in the control condition, $t(107)=2.04, p=.04, d=.40($ see Fig. 2).

\section{Discussion}

The findings from Study 3 supported our hypothesis that increased mating competition would amplify the degree to which women prioritize mating-relevant information offered by gay men versus other straight women. This finding accords with previous research findings demonstrating that women's perceptions shift in response to competitive mating threats (e.g., Bleske \& Shackelford, 2001; Fisher, 2013; Huchard \& Cowlishaw, 2010), and offers new experimental evidence that female mating competition likely influences women's psychology in the context of their relationships with gay men.

Because women place a greater premium on gay men's mating-related advice in competitive mating conditions, they may also perceive more value in forming friendships with gay men in this context. Stated differently, if women feel that they can receive unbiased mating-related advice from gay men, they should then be more motivated to befriend gay men when they perceive a greater degree of mating rivalry with other women. We designed and conducted a fourth study to provide insight into this question.

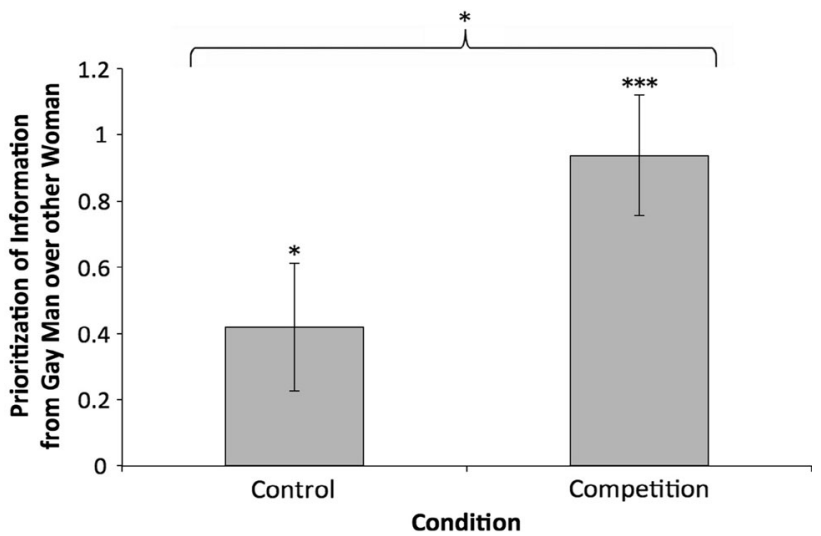

Fig. 2 Differential trust in gay men's and straight women's mating information as a function of mating competition (Study 3 ). The y-axis indicates the mean difference between women's trust in the gay man and the straight woman. Asterisks over individual conditions indicate that women trusted a gay man more than another straight woman. Asterisks above brackets indicate that this differential trust was amplified in the mating competition condition. Error bars represent \pm 1 SE. * $p<.05 ; * * * p<.001$

\section{Study 4: Perceptions of Mating Competition and Openness to Gay Male Friends}

Building on the findings from Study 3 , the aim of Study 4 was to examine whether women's perceptions of mating competition contributed to their willingness to befriend gay men. We predicted that women with heightened perceptions of mating competition would be more inclined to make gay male friends.

Even though our hypothesis points toward women being more open to forming friendships with gay men under competitive mating circumstances, it is also possible that women are open to making friends more generally in these situations. Because previous research has revealed that individuals receive great support from making friends (Demir \& Ozdemir, 2010; Gladow \& Ray, 1986), women who perceive greater difficulty finding a mate may therefore turn to others for guidance, reassurance, and counsel. However, because gay men may be the individuals who are most likely to offer unbiased insight and guidance related to mating pursuits, we predicted that women will be particularly open to gay male friendship in order to reap this unique benefit, particularly in the context of heightened mate competition.

\section{Method}

\section{Participants}

A total of 129 heterosexual women $\left(M_{\text {age }}=19.99\right.$ years, $S D_{\text {age }}=$ 3.35) participated in the study and received partial course credit for their participation. The sample was $27 \%$ Caucasian, $26 \%$ Hispanic, $18 \%$ African American, $14 \%$ Asian, and $15 \%$ of other ethnicities. 


\section{Measures and Procedure}

Perceptions of Mating Competition Eight items assessed the women's perceptions of intrasexual rivalry. For example, one item read, "I think women have to worry about competing with other women to find a decent guy" (see "Appendix 3" section for full list of items). The eight items were presented on 7-point Likert scales (endpoints: $1=$ strongly disagree, $7=$ strongly agree). The order of presentation was randomized. Responses were summed to form a composite measure of perception of intrasexual competition $(\alpha=.72)$, with higher values indicating higher ratings of perceived competition for mating partners.

Openness to Friendships Participants were asked about their openness to having friends of varying genders and sexual orientations. Specifically, participants were asked how open they would be to forming new friendships with straight women, straight men, gay men, and lesbian women. For each of these, participants were asked to rate their level of agreement with the following statements: (a) "I am open to making__friends", (b) "I would like to have___friends", (c) "I would like to spend time with____friends" and (d) "I would enjoy hanging out with____friends." Participants responded to these items on 7-point Likert scales (endpoints: $1=$ strongly disagree, $7=$ strongly agree).

Participants completed the study online. Before beginning the study, participants were told that they were taking part in an experiment examining their friendship preferences. As part of a larger study, they were asked to think about a particular friend and write about that friend for a period of $3 \mathrm{~min}$ and then complete the measures specified above. Because we had considered the possibility that women who already have close friendships with gay men are more open to befriending them, we also asked the women to provide a number of close gay male friends that they have had so we could control for its effect in our statistical model.

\section{Results}

Prior to statistical analysis, we screened out participants $(n=8)$ who consistently provided a single, specific response across both positively and negatively scored scale items (i.e., those who displayed acquiescent response bias) (Watson, 1992). Next, we created composite scores for women's openness to having straight female friends $(\alpha=.92)$, straight male friends ( $\alpha=.93)$, gay male friends $(\alpha=.96)$, and lesbian female friends $(\alpha=.96)$ by summing participants' scores on the four items assessing their openness to having each type of friend.

We then conducted a multiple regression analysis to examine whether women's perception of mating competition predicted their openness to having gay male friends independent of any friendships with gay men that they have had. Specifically, we entered women's perceptions of mating competition and their reported number of friendships with gay men as the two predictors in our regression model. As predicted, even after controlling for women's reported number of close friendships with gay men, $\beta=.38, S E=.14, t(118)=4.51, p<.001$, women's perceptions of mating competition still positively predicted their openness to forming new friendships with gay men, $\beta=.19$, $S E=.11, t(118)=2.26, p=.03$.

Further, in support of the idea that this finding did not merely reflect a general tendency to seek out friendship in competitive environments, there was no link between women's perceptions of intrasexual competition and their openness to forming friendships with straight women, straight men, or lesbian women (all $p \mathrm{~s} \geq .10$ ).

\section{Discussion}

Consistent with our Study 3 findings, the Study 4 data revealed that increased perceptions of mating competition among women were associated with a greater openness to making gay male friends. Crucially, this finding did not merely reflect a greater openness to making friends in general; increased perceptions of intrasexual rivalry were not associated with greater openness to forming friendships with straight women, straight men, or lesbian women.

\section{General Discussion}

The existing literature on the straight female-gay male relationship suggests that straight women experience an increased sense of comfort and trust when they are in the company of gay men (Grigoriou, 2004; Hopcke \& Rafaty, 1999). Alone, however, this descriptive finding does not offer an explanation for why women exhibit this heightened trust in gay men nor when (i.e., in what contexts) this effect occurs. To explain this phenomenon, we advanced and tested the hypothesis that it is specifically the absence of gay men's ulterior mating motivations that underlies this effect. Based on this hypothesis, we reasoned (1) that women's heightened trust in gay men should be specific to the mating domain (Study 1); (2) that the lack of gay men's motives to sexually and competitively deceive women should contribute to women's perception of gay men as being more sincere than straight men and straight women (Study 2); (3) that women's perception of increased mating competition should amplify women's greater trust of gay men's mating advice (Study 3); and (4) that heightened perceptions of mating competition should be associated with an increased openness to befriend gay men-but not other individuals (Study 4).

Collectively, the data from the four studies supported the rather varied predictions we derived from our central hypothesis that gay men's lack of motives to mate with women or compete with them for mates enhances women's trust in gay men 
and women's willingness to befriend them. Although one might attempt to develop an alternative explanation of any one of the findings we have reported here, we believe that the explanation we have proposed is the most parsimonious, the most theoretically coherent, and-ultimately - the most compelling when applied to the entire pattern of results across these four studies.

\section{Limitations and Future Directions}

Although the present findings make a strong preliminary case for our interpretation of why straight women form unique, trusting friendships with gay men, more research remains to be done. First, it is important to determine whether the present findings will generalize to other age groups of heterosexual women and to non-college samples. Previous literature indicates that the close friendship between straight women and gay men is not limited to the period of young adulthood (Gaiba, 2008; Muraco, 2012) and is evident in other cultures (e.g., in the Philippines) (Torre \& Manalastas, 2013); however, the specific hypothesis that we have proposed needs to be tested outside of the laboratory setting, using more diverse samples.

Second, a similar question applies to our Study 1 finding that women's trust in gay men's advice was specific to the domain of mating - an effect that did not generalize to the non-matingrelated domain of career advice. It will be important to explore the boundary conditions for this effect-specifically, whether other important domains of life may also influence women to trust gay men more than other individuals. The rationale behind our hypothesis suggests that women's trust in gay men should be most pronounced where there is an increased likelihood of being deceived by individuals harboring sexual or competitive motives (i.e., straight men and other straight women, respectively). However, straight women may not view gay men as trustworthy in domains of life where they perceive each other as adversaries or competitors (e.g., they are both being considered for the same job) or have equal reason to trust gay men versus other straight women or men (e.g., offering studying advice before an exam). Therefore, it is unlikely that contexts outside of the mating domain would also evoke a preferential trust in gay men in comparison to other straight women or to straight men.

Third, it is important to note that gay men's mating advice to women may not always be free of bias. Such bias might occur in cases that offer exceptions to the general rule; gay men could potentially bias mating-relevant information that they offer to straight women for reasons that are not associated with self-serving sexual interest or mating competition. For example, if a straight woman is interested in having a romantic relationship with a gay man's straight male friend, the gay male might deliberately provide flawed mating advice to the woman because of his concern that the romantic relationship would intrude upon quality time that he could spend with his straight male friend. Therefore, it will be important to further explore the specific cir- cumstances under which gay men would not likely offer straight women optimal advice for attracting straight male partners.

Fourth, future research should examine whether women's trust in gay men's mating advice gradually extends to other domains of life over time. Although previous research suggests widely varying trajectories in how trust in relationships changes over time (Vanneste, Puranam, \& Kretschmer, 2014), generalized trust between two people appears to increase as they learn to become more confident about each other's trustworthiness (Lewicki \& Bunker, 1995). Therefore, gay men's trustworthiness with regard to mating may eventually extend to many other life domains as their friendships with straight women progress.

Finally, the present findings have important implications for future research in gay-straight friendships. For example, the Study 4 findings demonstrated that women's perceptions of intrasexual competition were related to their openness to form friendships with gay men. However, due to the correlational nature of this study, we cannot state conclusively that female intrasexual competition causes women to befriend gay men. Our reasoning suggests that the absence of mating competition between gay men and straight women increases the latter's willingness to form friendships with the former, but future research is needed to more conclusively establish the causal direction of this relationship.

\section{Conclusions}

Past literature has described a close connection between straight women and gay men. However, previous empirical research has neither offered a compelling explanation for this phenomenon nor provided a generative hypothesis that yields new, testable predictions that enable us identify the contexts in which it is most likely to occur. The present studies addressed both of these limitations. They offer a novel, theoretically anchored hypothesis that explains why straight women form trusting bonds with gay men, and specified, in advance, the conditions in which such bonds are most likely to form.

Although the current studies enhance our understanding about the close bond between straight women and gay men, we advocate for further study of gay-straight relationships. A seismic shift in society's attitudes toward gay and lesbian individuals has recently resulted in a Supreme Court ruling which makes no distinction between the legitimacy of same-sex and oppositesex marriages (Liptak, 2015). This landmark decision is the culmination of many previous court rulings in favor of gay marriage and related rights in the United States and in many other countries around the world (Bruni, 2015; Smith-Spark, Conlon, \& Black, 2015). The social acceptance of homosexual individuals is still a work in progress, however, and how these individuals are perceived by heterosexual women and men is therefore a timely and important issue to examine. Further, because gay-straight relationships are becoming more common as more young gay 
men and lesbian women express their sexual orientations to their family and peers, the empirical study of the dynamics of gay-straight relationships is essential for understanding these unique social processes. We hope that the present investigation will encourage additional research on gay-straight relationships_-an interesting, important, and understudied domain of psychology.

Acknowledgments We would like to thank Anna Park for her statistical advice and expertise. We would also like to thank Sarah Hill, Morgan Thurow, Michelle Clark, Brittany Carroll, Karen Lopez, Monica Sheehan, and three anonymous reviewers for their helpful recommendations.

\section{Appendix 1: Scenarios Relevant to Sexual and Competitive Deception-Study 2}

Note: "Alex" is the target.

\section{Scenarios Relevant to Sexual Deception}

(1) Imagine that you picked out something to wear to the party, but you are worried it may be too revealing. When you express this concern to Alex, he looks you up-and-down a few times and then says, "Your outfit looks good-it isn't too revealing."

(2) Imagine that you and Alex are mingling with other people at the party. You notice a really attractive man in the corner of the room, and you really want to introduce yourself. Alex notices you looking at this man and immediately tells you, "I know him, and I wouldn't go there. I' $m$ sure there is a better fit for you..."

(3) Imagine that you are mixing a drink for yourself. Alex approaches you with two drinks in hand. He hands one to you and tells you, "I made this one just for you... Don't worry, it doesn't have that much alcohol in it."

(4) Imagine that you sit down next to Alex on the couch while he is talking to someone else. Suddenly, you feel Alex's hand caress your leg. He turns to you, pulls his hand away and says: "Oh sorry, I thought you were my other friend..."

(5) Imagine that you and Alex are mingling with other party attendees about traveling. After the conversation comes to a close, Alex turns to you privately and asks: "Want to go upstairs to my friend's bedroom with me? Ihave some pretty cool pictures from our recent trip that I could show you..."

(6) Imagine that the party is coming to a close, and you are quite tipsy. You are thinking about calling a taxi to take you home. When you say goodbye to Alex, he tells you: "Don't worry-I will walk you to my place that's down the street. I will let you sleep there."

\section{Scenarios Relevant to Competitive Deception}

(1) Imagine that you misplaced the invitation to the party that you are about to attend, and you just decide to wear casual clothing. When you arrive to the party, you are horrified to find out everyone is in cocktail attire. You turn to Alex and express how you need to go home and change. Alex looks your clothes and then says: "You look great in what you're wearing."

(2) Imagine that you and Alex are mingling with other people at the party. You notice a really attractive man in the corner of the room, and you really want to introduce yourself. Alex notices you looking at this man. She/he immediately smiles and tells you: "Let me introduce myself to him, and I could put in a good word for you."

(3) Imagine that Alex approaches the attractive man that you had your eyes so that she/he can put in a good word for you. Alex comes back to tell you about his/her conversation with him and says: "I pointed you out to him, but he didn't seem interested. Darn..."

(4) Imagine that you are grabbing another drink and you see the attractive guy again in passing. You smile at him as he passes, but he gives you a strange look. When you walk to the bathroom, you notice some food was caught in your teeth. After removing the food from your teeth, you rush back out to the party and ask Alex why she/he didn't tell you that there was food in her teeth. Alex replies by saying, "Oh sorry... I didn't notice it from my angle."

(5) Imagine that you and Alex overhear a group of girls at the party talking about how attractive a guy is in the kitchen, so the two of you make your way over to the kitchen. To your surprise, the attractive guy looks your way and smiles at you. Alex notices him looking your way and then says to you: "I've heard he is a big player, so be careful because you seem like a great girl."

(6) Imagine that you begin talking with the cute guy at the party again. You end up exchanging numbers with him and he tells you to text him later tonight after the party. Excitedly, you tell Alex what happened. Alex tells you, "I wouldn't text him tonight...it's better for him to text you first."

\section{Appendix 2: Guided Visualization of Increased Mating Competition-Study 3}

\section{Where Have all the Good Men Gone?}

\section{By: Alexis Dale}

Let the hunt begin. According to a recent study conducted by the psychology department of University of Texas at Austin, women may need to add a new concern to their list: finding a romantic partner. According to Psychology Professor Robert Dunn, his newest body of research indicates an unusual increase in the ratio of females to males in the US, especially those born between the years 1985 and 1998. His research demonstrated that—among 
individuals in the 1985-1998 birth cohort-women make up $59 \%$ of the population while men are down to a paltry $41 \%$. "This has been a very unprecedented change in the status quo," said Mary Barker of the US Census Bureau. "The sex ratio has never been this imbalanced." Nowhere has this imbalance been more evident than on college campuses. Although the sex ratio on college campuses has been female biased for a number of years now, things have gotten progressively worse. Many college campuses in the U.S. now have twice as many women as they do men.

"I have been trying to find a decent boyfriend for a number of years now without any luck," says Ellie Houser, a student from the University of Texas at Austin. "At least now I can feel confident that the problem might not be me. It's that there are literally fewer quality men out there for the taking, and too many single women who are after them."

Despite our current economic turmoil, companies such as eHarmony and Match.com have reported some of their highest earnings in the 2012-2013 fiscal year. The female clients who use these dating websites voice their concerns. "It is tiring trying to compete against the same group of women for the few good guys that are out there; sometimes you need a dating service to do the work for you-even then, it is still difficult," says Sarah who is a single woman that uses Match.com.

\section{Control Article-Study 3}

\section{Night Owls Have More Nightmares, Study Claims}

\section{By: Alexis Dale}

The early bird might catch the worm because it sleeps better than the night owl, not just because it awakens earlier. At least that appears to be the case for humans, according to a new study. Researchers found that night owls — "evening-type individuals"are significantly more likely to suffer from poor sleep quality, daytime sleepiness and disturbing nightmares than early birds"morning-type individuals"- - or folks whose bedtime falls somewhere between the two. "Evening-type people have more nightmares because of their sleep patterns," says lead author Yavuz Selvi, assistant professor of psychiatry at Yuzuncu Yil University in Van, Turkey, whose paper was published online Aug. 25 in the journal, Sleep and Biological Rhythms. Staying awake late at night and waking up late in the morning disrupts the relationship between the body's internal clock and its ability to maintain normal sleep patterns, Selvi explains.

In other words, it really screws up your circadian rhythm. Nightmares usually awaken you, so if they occur frequently, you might begin to fear falling asleep, cutting into your snooze time even more. Epidemiological studies have found that nearly nine in 10 adults reporting having at least one nightmare in the pre- vious year, Selvi says, with $2-6 \%$ reporting weekly nightmares. He and his co-authors studied 264 medical students, ages 17 to 26 years old, who weren't yet dealing with crazy hours in their training. The researchers administered a battery of tests to assess whether the students were morning or evening types, the quality of their sleep and how frequently they experienced nightmares and how disturbing they were.

The tests revealed that 59 of the students were evening types, 67 morning types and the rest fell in the "intermediate" range. Men were more likely than women to be night owls; vice versa when it came to early birds.

\section{Appendix 3: Perceptions of Female Competition- Study 4}

(1) I think there is a lot of competition to find someone desirable to date.

(2) I think women have to worry about competing with other women to find a decent guy.

(3) Ifeel like some women would lie in order to get a desirable guy.

(4) I think women easily get into confrontations over a particular man.

(5) I could see women belittling one another in front of an attractive guy.

(6) I think it is safe for women to trust one another when looking for men to date.*

(7) I don't think women have to worry much about having mutual interests in the same man.*

(8) I would feel threatened if my date started chatting with another woman.

*Indicates items that were reverse-scored.

\section{References}

Abbey, A. (1982). Sex differences in attributions for friendly behavior: Do males misperceive females' friendliness? Journal of Personality and Social Psychology, 32, 830-838.

Bleske, A. L., \& Shackelford, T. K. (2001). Poaching, promiscuity, and deceit: Combating mating rivalry in same-sex friendships. Personal Relationships, 8, 407-424.

Bruni, F. (2015, June 20). Gay marriage's moment. New York Times. Retrieved from http://www.nytimes.com/2015/06/21/opinion/sun day/frank-bruni-gay-marriages-moment.html?_r=0.

Buss, D. M. (1988). The evolution of human intrasexual competition: Tactics of mate attraction. Journal of Personality and Social Psychology, 54, 616-628.

Buss, D. M., \& Dedden, L. A. (1990). Derogation of competitors. Journal of Social and Personal Relationships, 7, 395-422.

Colquitt, J., Scott, B., \& LePine, J. (2007). Trust, trustworthiness, and trust propensity: A meta-analytic test of their unique relationships with risk taking and job performance. Journal of Applied Psychology, 92, 909-927.

De Block, A., \& Dewitte, S. (2007). Mating games: Cultural evolution and sexual selection. Biology and Philosophy, 22, 475-491. 
de Jong, K., Forsgren, E., Sandvik, H., \& Amundsen, T. (2012). Measuring mating competition correctly: Available evidence supports operational sex ratio theory. Behavioral Ecology, 23, 1170-1177.

de la Cruz, M., \& Dolby, T. (2007). Girls who like boys who like boys: True tales of love, lust, and friendship between women and gaymen. New York: Dutton.

Demir, M., \& Ozdemir, M. (2010). Friendship, need satisfaction and happiness. Journal of Happiness Studies, 11, 243-259.

DeSouza, E. R., Pierce, T., Zanelli, J. C., \& Hutz, C. (1992). Perceived sexual intent in the U.S. and Brazil as a function of nature of encounter, subjects' nationality, and gender. Journal of Sex Research, 29, 251-260.

Fisher, M. L. (2013). Women's intrasexual competition for males. In M. L. Fisher, J. R. Garcia, \& R. Sokol Chang (Eds.), Evolution's empress: Darwinian perspectives on the nature of women (pp. 1942). New York: Oxford University Press.

Fisher, M., \& Cox, A. (2010). Four strategies used during intrasexual competition for mates. Personal Relationships, 18, 20-38.

Gaiba, F. (2008). Straight women and gay men friends: A qualitative study. Dissertation Abstracts International Section A, 69, 262.

Gladow, N. W., \& Ray, M. P. (1986). The impact of informal support systems on the well-being of low-income single parents. Journal of Applied Family and Child Studies: Family Relations, 35, 113-123.

Grigoriou, T. (2004). Friendship between gay men and heterosexual women: An interpretive phenomenological analysis. London, England: London South Bank University, Families and Social Capital ESRC Research Group.

Hopcke, R. H., \& Rafaty, L. (1999). Straight women, gaymen: Absolutely fabulous friendships. Berkley, CA: Wildcat Canyon Press.

Huchard, E., \& Cowlishaw, G. (2010). Female-female aggression around mating: An extra cost of sociality in a multimale primate society. $B e$ havioral Ecology, 22, 1003-1011.

Lewicki, R. J., \& Bunker, B. B. (1995). Trust in relationships: A model of development and decline. In B. B. Bunker \& J. Z. Rubin (Eds.), Conflict, cooperation and justice (pp. 133-173). San Francisco, CA: Jossey-Bass.

Liptak, A. (2015, June 26). Gay marriage supporters win supreme court victory. New York Times. Retrieved from http://www.nytimes.com/ 2015/06/27/us/supreme-court-same-sex-marriage.html?_r=0.

Maitland, S. (1991). Fag-hags: A field guide. Critical Quarterly, 33, 19-25.

Malone, J. (1980). Straight women/gay men: A special relationship. New York: Dial Press.
Mayer, R., Davis, J., \& Schoorman, F. (1995). An integrative model of organizational trust. Academy of Management Review, 20, 709-734.

Moon, D. (1995). Insult and inclusion: The term fag hag and the gay male “community". Social Forces, 74, 487-510.

Muraco, A. (2004). Friendship matters: A study of close intersectional bonds. Unpublished doctoral dissertation, University of California Davis, Davis, CA.

Muraco, A. (2012). Odd couples: Friendships at the intersection of gender and sexual orientation. Durham, NC: Duke University Press Books.

Rumens, N. (2008). The complexities of friendship: Exploring how gay men make sense of their workplace friendships with straight women. Culture and Organization, 14, 79-85.

Russell, E. M., DelPriore, D. J., Butterfield, M. E., \& Hill, S. E. (2013). Friends with benefits, but without the sex: Straight women and gay men exchange trustworthy mating advice. Evolutionary Psychology, 11, 132-147.

Singleton, D. (2005). Behind every great woman there's a fabulous gay man: Advice from a guy who gives it to you straight. New York: Penguin.

Smith-Spark, L., Conlon, K., \& Black, P. (2015, May 23). Ireland votes overwhelmingly in favor of same-sex marriage. $C N N$. Retrieved from http://www.cnn.com/2015/05/23/europe/ireland-referendum-samesex-marriage/.

Thompson, D. (2004). Calling all fag hags: From identity politics to identification politics. Social Semiotics, 14, 37-48.

Torre, B. A., \& Manalastas, E. J. (2013). Babaeng bakla: Friendships between women and gay men in Philippines. Philippine Journal of Psychology, 46, 149-163.

Vanneste, B. S., Puranam, P., \& Kretschmer, T. (2014). Trust over time in exchange relationships: Meta-analysis and theory. Strategic Management Journal, 35, 1891-1902.

Walters, S., \& Crawford, C. (1994). The importance of mate attraction for intrasexual competition in men and women. Ethology and Sociobiology, 15, 5-30.

Warren, C. A. (1976). Women among men: Females in the male homosexual community. Archives of Sexual Behavior, 5, 157-169.

Watson, D. (1992). Correcting for acquiescent response bias in the absence of a balanced scale: An application to class consciousness. Sociological Methods Research, 21, 52-88.

Wilson, E. (2005, December 8). In fashion, who really gets ahead? New York Times, pp. G1, G11. 